OPEN ACCESS

Edited by:

Francisco Airton Castro Rocha,

Federal University of Ceará, Brazil

Reviewed by: Valderilio feijó Azevedo,

Federal University of Paraná, Brazil Claudio Arnaldo Len, Federal University of São Paulo, Brazil

*Correspondence:

Judith A. Smith

jsmith27@wisc.edu

Specialty section

This article was submitted to Rheumatology,

a section of the journal

Frontiers in Medicine

Received: 15 March 2021 Accepted: 30 April 2021 Published: 28 May 2021

Citation:

Smith JA and Burgos-Vargas R (2021)

Outcomes in Juvenile-Onset Spondyloarthritis.

Front. Med. 8:680916.

doi: $10.3389 /$ fmed.2021.680916

\section{Outcomes in Juvenile-Onset Spondyloarthritis}

\author{
Judith A. Smith ${ }^{1 *}$ and Ruben Burgos-Vargas ${ }^{2}$ \\ ${ }^{1}$ Department of Pediatrics, University of Wisconsin School of Medicine and Public Health, Madison, WI, United States, \\ ${ }^{2}$ Departamento de Reumatologia, Hospital General de Mexico, Mexico City, Mexico
}

Some studies have suggested children with juvenile onset spondyloarthritis (JoSpA) have a relatively poor outcome compared to other juvenile idiopathic arthritis (JIA) categories, in regards to functional status and failure to attain remission. Thus, in the interest of earlier recognition and risk stratification, awareness of the unique characteristics of this group is critical. Herein, we review the clinical burden of disease, prognostic indicators and outcomes in JoSpA. Of note, although children exhibit less axial disease at onset compared to adults with spondyloarthritis (SpA), 34-62\% have magnetic resonance imaging (MRI) evidence for active inflammation in the absence of reported back pain. Furthermore, some studies have reported that more than half of children with "enthesitis related arthritis" (ERA) develop axial disease within 5 years of diagnosis. Axial disease, and more specifically sacroiliitis, portends continued active disease. The advent of TNF inhibitors has promised to be a "game changer," given their relatively high efficacy for enthesitis and axial disease. However, the real world experience in various cohorts since the introduction of more widespread TNF inhibitor usage, in which greater than a third still have persistently active disease, suggests there is still work to be done in developing new therapies and improving the outlook for JoSpA.

Keywords: juvenile spondyloarthritis, enthesitis-related arthritis (ERA), disease manifestations and outcomes, prognosis, TNF inhibitor, sacroiliitis

\section{INTRODUCTION}

As a whole, the group of children with JoSpA/ERA have worse reported outcomes than other categories of juvenile idiopathic arthritis (JIA) in regards to remission rates, pain, and quality of life $(1,2)$. Some of the challenges for this group derive from treatment-refractory complications and insidious, sometimes asymptomatic axial disease progression in JoSpA/ERA. The long lag between symptom onset and diagnosis remains problematic as well $(3,4)$. Greater awareness of the unique clinical attributes in JoSpA/ERA could aid providers in stratifying their patients toward more aggressive therapy. It is also important to identify unmet clinical needs regarding outcomes. Although the therapeutic options have changed over time with the advent of biologics, the real-world impact on outcome is not clear. Thus, the goals of this review are to highlight the clinical characteristics of this group that contribute to the burden of disease, prognostic indicators, and the remaining gaps in outcomes.

In adults, axial SpA encompasses a spectrum of symptoms including pain and stiffness affecting the spinal and sacroiliac joints and axial entheses, and more rarely peripheral arthritis and enthesitis. Familial aggregation (genetics) and significant association with HLA-B27 antigen play 
an important role in the pathogenesis of the disease (5-7). Besides musculoskeletal involvement, adults with SpA have a variable percentage of anterior uveitis, psoriasis, and gut disease (8). Children and adolescents, by definition those with disease onset $\leq$ to 18 years of age, present with clinical disease that clearly overlaps with this adult spectrum, although with some differences, likely reflecting the developing immune system, mechanical differences and potentially the microbiome $(9,10)$. However, because of some of these key clinical differences, the adult classification criteria, particularly those for axial $\mathrm{SpA}$, may not perform particularly well in capturing children. For instance, inflammatory back pain (by definition, pain for more than 3 months), which serves as an entry point for adult disease, is much less common in children early in their disease course (11-13). Related to the lower frequency of sacroiliitis at disease onset in juvenile Spondyloarthritis (JoSpA), one group has reported a sensitivity of only $25 \%$ for ASAS axial SpA criteria (14). The ASAS peripheral SpA critera may perform better in children, capturing $>90 \%$ of subjects (15-17). Unfortunately, there is currently no official JoSpA classification equivalent. The current $\mathrm{SpA}$ monikers and classification criteria applied to children is a muddle, including a pot-pourri of terms such as "seronegative enthesopathy and arthropathy" (SEA syndrome), "enthesitis related arthropathy" (ERA), and worse yet, "undifferentiated arthritis" (18). The problems surrounding nomenclature are described in detail in chapter 1 of this issue and so will not be addressed further here. In this chapter, we will generally use the inclusive acronym JoSpA/ERA (juvenile onset spondyloarthritis/ERA), unless specific International League Against Rheumatism (ILAR) classification categories (e.g., ERA, PsA, undifferentiated arthritis) are being described Petty et al. (19).

\section{AXIAL AND PERIPHERAL ARTHRITIS AND ENTHESITIS IN JOSPA/ERA}

Compared with other types of JIA, children with JoSpA/ERA have a higher male representation and older age of onset (typically 10-11 years) (basic clinical characteristics in Table 1) $(18,20,25,29,30)$. HLA-B27 positivity in various JoSpA/ERA cohorts and case series is variable, potentially reflecting ethnic differences. For instance HLA-B27 is present in $\sim 6-8 \%$ in Europeans, but rare in Africans and in Japanese $(<1 \%)(31)$. In general, the prevalence of ankylosing spondylitis (AS) and other related SpA conditions strongly associates with HLAB27 antigen in different populations around the world (32). Although in some populations, for instance in Africans, SpA may associate more with other HLA molecules (e.g., HLAB14:03) (33). In the multi-national studies cited here, HLAB27 prevalence ranges from 35 to $97 \%$ [see Table 1 and (26)]. Despite this ethnic variability, HLA-B27 still accounts for the greatest known influence on genetic susceptibility to AS and SpA $(6,34,35)$, and is overrepresented in children with SpA compared to the general population $(30,36,37)$. Moreover, distribution of HLA-B27 disease-associated subtypes in JoAS (juvenile onset ankylosing spondylitis) mirrors the prevalence in subjects with adult onset AS (36).

In comparison with adult onset AS, children with JoAS tend to present with more enthesitis and peripheral arthritis and less lumbar pain and stiffness, a pattern also characteristic of the greater spectrum of JoSpA/ERA $(4,11,38)$. Presence of enthesitis varies by study location and definition of $\mathrm{SpA}$, ranging from $37 \%$ in ERA to $>100 \%$ in SEA (Table 1, with specific anatomic distribution described in Table 2) $(18,23)$. The most frequent areas of involvement are the calcaneal insertion of the Achilles tendon, patellar tendons and insertions of the plantar fascia. Clinical assessment of enthesitis can be challenging; however, ultrasound has been an extremely useful, though operatordependent adjunct, as has MRI $(41,42)$. Interestingly enthesitis is not exclusive to ERA. One of the largest studies to date on the topic of enthesitis in different JIA categories comes from Rumsey et al. (43). In a Canadian JIA inception cohort, enthesitis was defined by entheseal tenderness in more than one body site on more than one occasion during 60 months follow up. Enthesitis affected $16 \%$ of this large JIA cohort (1,406 patients), and ERA, PsA and undifferentiated arthritis accounted for 64,2 , and $18 \%$, respectively, of those with enthesitis. In this cohort, children with enthesitis tended to be older at disease onset (10.7 vs. 7.5 ), male ( 57 vs. $31 \%$ ), have polyarthritis (57 vs. $41 \%$ ), and sacroiliitis (30 vs. $4 \%)$. Within ERA, 141/202 (70\%) had enthesitis. In this JIA cohort, the most common anatomical locations were the plantar fascia (39\%), Achilles (31\%), and tibial tuberosity (30\%). The course of enthesitis tended to follow active joint count (43).

Regarding arthritis phenotype, children with JoSpA/ERA typically present with asymmetric oligoarticular arthritis affecting the large weight-bearing joints (knees), ankles, midfoot, and root joints (hips and shoulders) $(17,18,26,39,44)$. Table 2 presents the anatomic distribution described in several JoSpA/ERA cohorts and case series. In a long-term study from Norway, 73\% had oligoarticular onset, and in US and Taiwanese cohorts, 78 and $97 \%$ had oligo articular onset, respectively $(2,26,27)$. A few studies have reported $>50 \%$ prevalence of polyarticular involvement in JoSpA/ERA, and patients can accumulate 5 or more joints over time $(17,21,39,43)$. The most commonly affected joints include the knees (46-100\%) and ankles/subtalar joints (27-80\%). Hip arthritis is also common (19-83\%, Table 2) and can be relatively aggressive and severe (45). Indeed, 2 studies comparing juvenile and adult onset AS described increased rates of hip arthroplasty in the JoAS group (17.7 vs. $8.7 \%$ in the Genseler study and 17 vs. $4 \%$ in the Calin study), although no difference was reported in a Canadian study (7\% for both, O'Shea et al.) $(38,45,46)$.

Foot arthritis, particularly mid-foot arthritis or tarsitis, is highly characteristic of this population, though the prevalence varies depending upon the study (Table 2). Indeed, in one study comparing JoAS and other Juvenile Rheumatoid Arthritis (JRA), $85.7 \%$ of children with JoAS experienced tarsitis, vs. $10.7 \%$ in JRA within 1 year of presentation (39). Anatomic involvement of the feet was particularly well described in a study from India (40). Phatak et al. described a case series of 55 children diagnosed with ERA for $<60$ months. This population was $96 \%$ male and $80 \%$ HLA-B27 positive, with sex most likely skewed by referral 
TABLE 1 | JOSPA/ERA clinical features.

\begin{tabular}{|c|c|c|c|c|c|c|c|c|c|c|c|c|}
\hline Years (y) & Country & $\begin{array}{l}\text { Cohort/ } \\
\text { sample } \\
\text { size }\end{array}$ & $\mathrm{Yf} / \mathrm{u}$ & $\begin{array}{l}\text { SpA \#(\%) of } \\
\text { total cohort }\end{array}$ & $\begin{array}{l}\text { Age onset } \pm \text { SD } \\
\text { or }(25 \%, 75 \%) \text { or } \\
\text { (range) }\end{array}$ & $\%$ Male & $\begin{array}{l}\% \\
\text { HLA-B27 }\end{array}$ & $\begin{array}{l}\% \text { Spine } \\
\text { involved }^{\text {e }}\end{array}$ & $\begin{array}{l}\% \text { periph. } \\
\text { Arthritis }\end{array}$ & $\begin{array}{l}\% \\
\text { Enthesitis }\end{array}$ & $\begin{array}{l}\% \\
\text { Eye }\end{array}$ & References \\
\hline$<1982$ & Canada & 39 & 1.9 & 39 (100) SEA & $9.8(2,16)$ & 90 & 72 & $\begin{array}{l}44 \text { exam } \\
28 \text { X-ray SI } \\
15 \text { X-ray TL spine }\end{array}$ & 74 & 100 & 15 & (18) \\
\hline 1980-1985 & Norway & 175 & 15.3 & 55 (33) ERA & $11.1 \pm 2.8$ & 65 & 85 & $\begin{array}{l}35 \text { X-ray } \\
47 \text { IBP } \\
75 \\
\text { decreased mobility }\end{array}$ & - & - & - & (2) \\
\hline 1997-2000 & Nordic & 410 & 8 & $\begin{array}{l}46 \text { (11.2) ERA } \\
14(3.4) \text { PsA } \\
63(15.4) \text { UA }\end{array}$ & $\begin{array}{l}10.5(8.6,12.3) \\
5.9(3.2,7.2) \\
8.1(3.5,11.9)\end{array}$ & $\begin{array}{l}65.2 \\
50 \\
28.6\end{array}$ & $\begin{array}{l}72 \\
21 \\
21\end{array}$ & - & - & - & - & $(20,21)$ \\
\hline$<2001$ & England & 246 & 28 & $\begin{array}{l}32 \text { (13.1) ERA } \\
15 \text { (5.3) PsA }\end{array}$ & $\begin{array}{l}10.0 \pm 3.3 \\
9.9 \pm 3.3\end{array}$ & - & - & - & - & - & $\begin{array}{l}28 \\
23\end{array}$ & (22) \\
\hline 2002-2003 & Germany & 118 & 4 & $\begin{array}{l}118(100) \text { SpA } \\
(m N Y \text { or ESSG) }\end{array}$ & - & 73 & 66 & $32 \mathrm{IBP}$ & 96 & 44 & 6.8 & (17) \\
\hline 1994-2006 & India & 235 & $>1.5$ & $\begin{array}{l}84 \text { (36) ERA } \\
3 \text { (1) PsA } \\
11 \text { (5) UA }\end{array}$ & $\begin{array}{l}13(7,16) \\
12(5,12) \\
11(2-15.5)\end{array}$ & $\begin{array}{l}91 \\
33 \\
55\end{array}$ & $\begin{array}{l}89^{d} \\
- \\
40\end{array}$ & $\begin{array}{l}19 \mathrm{SI}, 37 \text { spine } \\
0 \\
18 \mathrm{SI}, 20 \text { spine }\end{array}$ & - & $\begin{array}{l}37^{\dagger} \\
0 \\
27\end{array}$ & $\begin{array}{l}8.3 \\
0 \\
0\end{array}$ & (23) \\
\hline 2000-2006 & Italy & 59 & 3 & 59 (100) ERA & $9.3(6.5-13.3)$ & 68 & 66 & $\begin{array}{l}36 \text { IBP or } \\
\text { decreased mobility } \\
\text { (in 1y) }\end{array}$ & - & - & - & (24) \\
\hline 2006-2009 & Brazil & 253 & & $\begin{array}{l}253 \text { (100) JSpA } \\
\text { (ESSG) }\end{array}$ & & 86 & 80 & $60 \mathrm{IBP}$ & $\begin{array}{l}60 \text { lower } \\
\text { limb, } 20 \\
\text { upper limb }\end{array}$ & 58 & 25 & (4) \\
\hline 1995-2010 & Taiwan & 195 & $>1.5$ & $\begin{array}{l}73 \text { (37) ERA } \\
3 \text { (1.5) PsA } \\
11 \text { (5) UA }\end{array}$ & $\begin{array}{l}10.8(8.9,12.3) \\
9.4(6.2,10.8) \\
10.2(8.7,15.1)\end{array}$ & $\begin{array}{l}85 \\
67 \\
20\end{array}$ & $\begin{array}{l}82 \\
33 \\
0\end{array}$ & $\begin{array}{l}48 \text { SI or lumbar } \\
33 \\
0\end{array}$ & - & - & $\begin{array}{l}9.6 \\
0 \\
0\end{array}$ & (25) \\
\hline 1989-2012 & USA & 234 & $-^{a}$ & 234 (100) ERA & - & 72 & 59 & $\begin{array}{l}26 \text { clinical SI } \\
56 \mathrm{MRI}\end{array}$ & 92 & 75 & 5.6 & (26) \\
\hline 2008-2015 & France & 114 & 2.5 & ERA/JSpAc & $9.6(6.9,12.3)$ & 59 & 43 & $\begin{array}{l}63 \text { ( } 47 \text { with SI, } 24 \\
\text { thoracic and } 44 \\
\text { lumbar) }\end{array}$ & 87 & 86 & - & (16) \\
\hline 1993-2018 & Taiwan & 181 & 7.7 & 72 (40) ERA & $11.0 \pm 3.2$ & 86 & 97 & $\begin{array}{l}16 \text { (clinical or X-ray } \\
\text { SI) }\end{array}$ & - & - & 10 & (27) \\
\hline
\end{tabular}

Cohorts/series are listed by years of patient recruitment and nationality in left columns. Unless otherwise indicated, features are cumulative at follow up rather than baseline. ILAR, International League against Rheumatism; ERA, enthesitis related arthritis; PSA, psoriatic arthritis; UA, undifferentiated arthritis. Follow up years refers to mean or median, depending upon the study. For cohorts not describing a specific manifestation (no data) or with insufficient data (based on $<1 \%$ ), the missing data are designated with a dash (-). IBP, inflammatory back pain; SI. sacroilitis.

${ }^{a}$ Cross-sectional study.

${ }^{b}$ Other JoSpA. SEA, seronegative enthesopathy and arthropathy; ESSG, European Spondyloarthropathy Study Group; Mny, modified New York criteria for ankylosing spondylitis (28).

CPhysican diagnosed JSPA. At last followup, 92\% met clinical criteria for ASAS peripheral SpA and 75\% for either ERA or PSA.

${ }^{d}$ Percentages are from 62 patients with ERA and 10 with PSA were tested for HLA-B27.

${ }^{e}$ Description of axial involvement was heterogeneous between sources and included symptoms, clinical assessment, radiology (X-ray), and MRI.

${ }^{f}$ Relatively low proportions of enthesitis in "ERA" are not explained. 
TABLE 2 | Anatomic distribution of peripheral arthritis and enthesitis.

\begin{tabular}{|c|c|c|c|c|c|c|c|c|}
\hline $\begin{array}{l}\text { Years }(y) \text { recruited } \\
\text { Country }\end{array}$ & $\begin{array}{l}<1982 \\
\text { Canada }\end{array}$ & $\begin{array}{l}\text { 1980-1985 } \\
\text { Mexico }\end{array}$ & $\begin{array}{l}\text { 2002-2003 } \\
\text { Germany }\end{array}$ & $\begin{array}{l}2000-2006 \\
\text { Italy }\end{array}$ & $\begin{array}{l}\text { 1995-2010 } \\
\text { Taiwan }\end{array}$ & $\begin{array}{l}\text { 1989-2012 } \\
\text { USA }\end{array}$ & $\begin{array}{l}\text { 2008-2015 } \\
\text { France }\end{array}$ & $\begin{array}{l}\text { 2015-2016 } \\
\text { India }\end{array}$ \\
\hline Cohort size & 39 & 110 & 118 & 59 & 195 & 234 & 114 & 55 \\
\hline SpA \# (\%) & All SEA & 35(32) JoAS & All SpA mNY or ESSG & All ERA & 73(37) ERA & All ERA & All SpA & All ERA \\
\hline \multicolumn{9}{|l|}{ Peripheral arthritis } \\
\hline$\% \mathrm{Hip}$ & - & 83 & 38 & - & 43 & 19 & 46 & - \\
\hline$\%$ Mid-foot & - & 89 & 9.3 & 58 & - & - & 9 & $\begin{array}{l}36 \text { by ultrasound } \\
54 \text { by MRI }\end{array}$ \\
\hline$\%$ Fingers & - & 23 & 25 & - & $18^{\mathrm{a}}$ & - & 12 & - \\
\hline$\%$ Toes or MTP & - & 86 & 27 & - & $16^{\mathrm{a}}$ & - & 17 & 4 toes 16 MTP \\
\hline \% Plantar front insertion & - & - & & - & & - & 39 & $20^{d}$ See note \\
\hline \% Plantar calcaneal insertion & 67 & 54 & & 38 & & - & See note ${ }^{c}$ & See note ${ }^{d}$ \\
\hline$\%$ Knee & 49 & 23 & & - & & 44 & 46 & - \\
\hline$\%$ Pelvis & 5 & 9 & & - & & 30 & $22^{\mathrm{C}}$ & - \\
\hline$\%$ Greater trochanter & - & 14 & & - & & - & See Note ${ }^{c}$ & - \\
\hline References & (18) & (39) & (17) & (24) & (25) & (26) & (16) & (40) \\
\hline
\end{tabular}

Cohorts are listed across the top by years of recruitment and nationality. ERA, enthesitis related arthritis; ESSG, European Spondyloarthropathy Study Group; mNY, modified New York criteria for ankylosing spondylitis (28). ASAS, Assessment of Spondyloarthritis International Society; F/u, median or mean follow up, depending upon the study; MTP, metatarsalphalangeal joints. No data or insufficient data (<1\%) designated as -. Knee includes tibial tuberosity, infrapatellar, and suprapatellar sites. Pelvis includes ischial tuberosity, iliac crest, and interosseous ligaments of sacroiliac joint.

a Specified as "small joints" of fingers or feet.

${ }^{b}$ Cross sectional inception cohort without specified follow up.

c74\% had Achilles or plantar calcaneal insertion enthesitis. "Pelvis" was lumped with greater trochanteric enthesitis in this study.

${ }^{d}$ Not specified if frontal or calcaneal plantar fasciitis.

bias. This sex bias may over-represent the incidence of this complication in JSpA but anatomic distribution should still be generally informative. Foot pain occurred at presentation in 56\% and another $27 \%$ developed foot pain during $<5$ y follow up. Foot/ankle arthritis was apparent by exam in $65 \%$, with taloAchilles enthesitis in $47 \%$ and plantar fasciitis in $20 \%$. Ultrasound was abnormal in 56\% and MRI in 54\%. Most of the MRIs that were positive in clinically asymptomatic subjects only had bone marrow edema, which may or may not have been pathologic. By exam, the most commonly involved arthritic joints were the midfoot (44\%) followed by tibiotalar (27\%), subtalar (15\%), and MTP (16\%). By ultrasound and MRI, the most commonly affected joints were talonavicular and tibiotalar, followed by calcaneocuboid and subtalar. Ankle arthritis prevalence was $27 \%$. In those with mid-foot disease, half had mid-foot enthesitis and $2 / 3$ tenosynovitis. Foot involvement correlated with significant functional impact, based on their juvenile arthritis foot index (JAFI). None of the children received biologics. There was no correlation with sacroiliitis or HLA-B27. Similar early prevalence was described in a Spanish cohort, where $35 \%$ had tarsitis at presentation (47). In this series, the children with tarsitis were much less likely to present with axial pain (8 vs. 54\%) or develop axial involvement, and were often initially misdiagnosed with infection. These results contrast with those obtained by BurgosVargas et al., in which tarsitis (in conjunction with enthesitis) was highly predictive of a diagnosis of AS at 10 years (39).

"Inflammatory Back Pain" seldom occurs in children. In addition, some of the metrics used to follow adults are not helpful in children. For instance, in one study, chest expansion was the same for children with JoAS and SEA and healthy children (48). Moreover, there is poor correlation between symptoms, exam findings and disease indicated by MRI, making clinical assessment challenging (49). However, it is important to maintain a high index of suspicion during initial assessment and to remain vigilant for the development of axial disease. A significant portion of children with JoSpA/ERA have axial involvement at presentation or develop axial disease within the first 5 years, with some variability by study. For example, in the predominantly male and HLA-B27+ ERA case series from India, 55\% had inflammatory back pain (IBP) and 38\% clinical sacroiliitis during the first 5 years of disease (mean duration of disease 1.9 years) (40). Of these, $33 \%$ had radiographic sacroilitis. In one of 
the largest multinational MRI-imaged inception cohort of 540 children with clinically suspected JoSpA, 20\% had sacroiliitis. Interestingly $42 \%$ had incidental findings unrelated to the sacroiliac joints that potentially contributed to axial symptoms, including enthesitis, hip arthritis, and degenerative disease (50). Even in cohorts where sacroiliitis incidence was initially $<30 \%$, more than half of the subjects developed axial disease within 5 years (16). In a 1989 report, in an SEA cohort of 20 children, $47 \%$ fulfilled modified NY criteria for ankylosing spondylitis (evidence by X-ray) within 3 years, $75 \%$ in 5 years and $>90 \%$ in long-term follow up (51). In another study of children with JoAS, only $14 \%$ had lumber or sacroiliac pain 1 year after disease onset, although $100 \%$ reported sacroiliac/lumbar symptoms by 10 years (39).

Recent MRI-imaging studies of children with JoSpA/ERA have revealed an alarming percentage with asymptomatic axial disease. In a SpA cohort reported by Weiss at al. 20\% had MRI-detected active sacroiliac disease at presentation. A high proportion $(88 \%)$ of these cases already exhibited erosions, but only $38 \%$ of those with positive MRIs reported any back symptoms (49). In another cohort of 143 JoSpA patients, 53 (37\%) of the patients had imaging or clinical suggestions of axial involvement. Eighteen had abnormal sacroiliac X-rays and 20 had sacroiliitis by MRI (32 total with abnormal imaging), but a third of these (11) had no back symptoms (52). Given the prevalence of axial inflammation at baseline, propensity for developing axial disease, and occurrence of axial disease in the absence of reported back pain in some children, there should be a low threshold for evaluating children with JoSpA/ERA by MRI. In adults with AS, early disease is a time-limited opportunity to gain the greatest response from biologic medication such as TNF inhibitors $(53,54)$. Unfortunately lag between symptom onset and diagnosis is even longer in children than in adults (8-9 vs. 5 years $)(3,55)$.

\section{EXTRA-ARTICULAR MANIFESTATIONS}

Depending upon the study and length of follow up, uveitis has been reported in $5-28 \%$ of JoSpA/ERA subjects $[(22,26)$, Table 1]. A comprehensive cross-sectional/retrospective study came out recently describing uveitis among 118 children with JoSpA, including ERA (62\% of the SpA cases), PsA (18\% of the cases), undifferentiated arthritis (14\%), and IBD-associated arthritis (6\%). Uveitis was reported in 24 subjects (11\%), with the highest proportion in ERA (13\% of those patients) and $7 \%$ in the other ILAR SpA categories. Seventy nine percent of the uveitis was symptomatic. HLA-B27 prevalence, at $45 \%$, was similar between groups and did not correlate with likelihood of uveitis, nor with symptomatic uveitis (56).

Skin and nail involvement characterizes the PsA ILAR subgroup. Clinical manifestations for this subgroup have been reviewed extensively elsewhere and will not be described in detail here (57-59). Briefly, children with nail involvement may exhibit nail pitting and onycholysis. Children do not always manifest the pathognomonic discrete erythematous scaly plaques. Psoriasis may be subtle and confused with eczema in children. Places that may exhibit scaling are along the hairline, behind the ears, around the umbilicus and intergluteal cleft. Dactylitis, or diffusely swollen "sausage" digits are also common in children with PsA. Prevalence in JSpA overall is $\sim 10 \%$ (Table 2) $(16,17,40$ ).

In adults, between 6 and $14 \%$ of patients with AS develop frank IBD (60). However, colonoscopies from asymptomatic or mildly symptomatic patients have revealed a shocking prevalence of subclinical inflammation in $\sim 60 \%$ of subjects (61). These findings and other studies have suggested the potential involvement of a gut-joint axis in disease pathogenesis $(62,63)$. In children, gut involvement in JoSpA/ERA is less clear, not the least because of the difficulties in classification. However, one study found $67 \%$ of children with ERA had elevated calprotectin compared to $18 \%$ in other types of JIA, supporting the concept of a disease continuum between childhood and adult onset SpA $(15,64)$.

Heart disease is certainly less common in children with AS vs. adults, though a 1995 study in a 36 patients with JoAS revealed 2 patients with mild mitral regurgitation and 3 with aortic regurgitation (65). None had functional impact or conduction abnormalities. In the initial description of SEA, 2 of 39 subjects (5\%) had aortic insufficiency (18). By way of comparison, $5-10 \%$ of adults with AS have a conduction disorder or aortic insufficiency (66). Although functional cardiac complications may be relatively infrequent in JoSpA/ERA, these studies suggests the heart might be an organ worth monitoring in children. At the very least, more data on this topic would be helpful.

\section{PROGNOSTIC INDICATORS AND OUTCOMES}

Various studies, particularly those from before the biologic era, paint a relatively dismal prognosis for children with SpA (Table 3), particularly when considering disability, pain, and remission rates. In a long-term Norwegian cohort, at 15 years patients had a lower level of physical function indicated by HAQ scores (0.38 vs. 0.16$)$ and poorer physical health (SF-36, 46.4, vs. 52.4) and pain (2.88 vs. 2.09 on 1-6 scale) vs. polyarticular and oligoarticular JIA (2). In the 30-year follow up of that same cohort comparing ILAR subgroups, only $37 \%$ of ERA patients were in remission off medications, and the only group that fared worse than ERA was RF+ poly JIA (67). Similarly, in a large cross-sectional study using CARRA registry data, Weiss et al. reported that children with ERA had worse pain, function (CHAQ) and health status than other forms of JIA (1). In the Canadian ReACCh-Out JIA cohort, a diagnosis of ERA carried an OR of 0.67 and undifferentiated arthritis an OR of 0.49 for attaining inactive disease (72).

Multiple studies point to baseline enthesitis as a poor prognostic indicator, despite its responsiveness to current therapeutic approaches $(1,43,71,73)$. One possible explanation for this association is that enthesitis often portends sacroiliitis (16). Indeed, several studies have directly implicated sacroiliitis as a poor prognostic indicator. In a Taiwanese JIA cohort followed over 8 years, any sign of sacroiliitis (clinical or radiologic) predicted active disease, as none of these subjects attained 
TABLE 3 | Remission vs active disease in Juvenile Spondyloarthritis cohorts.

\begin{tabular}{|c|c|c|c|c|c|c|c|c|c|c|c|}
\hline $\begin{array}{l}\text { Years } \\
\text { recruited }\end{array}$ & Country & $Y \mathrm{f} / \mathrm{u}$ & $\begin{array}{l}\text { SpA \#(\%) of total } \\
\text { cohort }\end{array}$ & $\begin{array}{l}\% \\
\text { Active }\end{array}$ & $\begin{array}{l}\text { \% Remission } \\
\text { (total) }\end{array}$ & $\begin{array}{l}\% \text { Remission } \\
\text { (on med) }\end{array}$ & $\begin{array}{l}\% \text { Remission } \\
\text { (off med) }\end{array}$ & $\begin{array}{l}\% \text { Continuous } \\
\text { active }\end{array}$ & $\begin{array}{l}\% \text { Remit for } \\
1 y \text { then flare }\end{array}$ & $\% \mathrm{TNFi}$ & References \\
\hline 1980-1985 & Norway & 15.3 & 55(33) ERA & 56 & 44 & - & - & - & - & 0 & (2) \\
\hline 1980-1985 & Norway & 30 & $\begin{array}{l}27(15) \text { ERA } \\
21(12) \text { PsA } \\
11(6) \text { UA }\end{array}$ & - & - & - & $\begin{array}{l}37 \\
48 \\
64\end{array}$ & - & - & 0 & (67) \\
\hline 1970-1998 & Italy & 10 & $\begin{array}{l}67 \text { (10) SpA } \\
\text { (ILAR/ESSG) }\end{array}$ & 64 & 36 & - & - & 52 & 15 & - & (68) \\
\hline $1997-2000$ & Nordic & 7 & $\begin{array}{l}\text { 49(11) ERA } \\
\text { 14(3.2) PsA } \\
66(15) \text { UA }\end{array}$ & $\begin{array}{l}61 \\
54 \\
53\end{array}$ & $\begin{array}{l}39 \\
46 \\
47\end{array}$ & $\begin{array}{l}8 \\
23 \\
6\end{array}$ & $\begin{array}{l}31 \\
23 \\
41\end{array}$ & $\begin{array}{l}31 \\
27 \\
40\end{array}$ & - & $\begin{array}{l}17.5 \text { for all } \\
\text { JIA }\end{array}$ & (20) \\
\hline 2002-2003 & Germany & 4 & $\begin{array}{l}118 \mathrm{SpA} \text { (mNY or } \\
\text { ESSG) }\end{array}$ & $54^{a}$ & - & $43^{a}$ & $23^{a}$ & - & 14 & 6 & (17) \\
\hline 1995-2010 & Taiwan & $>1.5$ & $\begin{array}{l}\text { 73(37) ERA } \\
3(1.5) \text { PsA } \\
5(2.6) \cup A\end{array}$ & $\begin{array}{l}56 \\
0 \\
20\end{array}$ & $\begin{array}{l}44 \\
100 \\
80\end{array}$ & $\begin{array}{l}11 \\
33 \\
0\end{array}$ & $\begin{array}{l}33 \\
67 \\
80\end{array}$ & $\begin{array}{l}48 \\
0 \\
0\end{array}$ & $\begin{array}{l}8 \\
0 \\
20\end{array}$ & $\begin{array}{l}12.8 \text { for all } \\
\text { JIA }\end{array}$ & (25) \\
\hline 2005-2010 & Canada & 5 & $\begin{array}{l}\text { 157(14) ERA } \\
64(6) \text { PsA } \\
110(10) \text { UA }\end{array}$ & $\begin{array}{l}53 \\
53 \\
54\end{array}$ & $\begin{array}{l}47 \\
47 \\
46\end{array}$ & - & - & - & - & $<20$ & (69) \\
\hline 2005-2010 & $\begin{array}{l}\text { Canada (2 of } \\
\text { above centers) }\end{array}$ & 5.6 & $\begin{array}{l}\text { 52(21) ERA } \\
\text { 10(4) PsA } \\
\text { 13(5) US }\end{array}$ & $\begin{array}{l}35 \\
20 \\
15\end{array}$ & $\begin{array}{l}65 \\
80 \\
69\end{array}$ & $\begin{array}{l}13 \\
30 \\
15\end{array}$ & $\begin{array}{l}52 \\
50 \\
54\end{array}$ & - & - & 22 for all JIA & (70) \\
\hline 2013-2014 & Germany & 1 & $\begin{array}{l}\text { 74(11) ERA } \\
\text { 28(4) PsA } \\
50(7) \text { UA }\end{array}$ & $\begin{array}{l}72 \\
73 \\
58\end{array}$ & $\begin{array}{l}28^{b} \\
29 \\
42\end{array}$ & - & - & - & - & $\begin{array}{l}25 \\
32 \\
36\end{array}$ & (71) \\
\hline 2008-2015 & France & 2.6 & 114 ERA or ASAS & 45 & 55 & 35 & 20 & - & - & 42 & (16) \\
\hline 1993-2018 & Taiwan & 7.7 & $\begin{array}{l}\text { 73(40) ERA } \\
1(0.5) \text { PsA } \\
1(0.5) \text { UA }\end{array}$ & 66 & 34 & 7 & 27 & - & - & 78 & (27) \\
\hline
\end{tabular}

Cohorts are listed by years of patient recruitment and cohort nationality (left columns).

Cohort acronyms: GESPIC, German Spondyloarthritis Inception Cohort; ReACCh-Out, Research in Arthritis in Canadian Children Emphasizing Outcomes); ICON, Inception Cohort of Newly Diagnosed Children with JIA; JCA, juvenile chronic arthritis; JRA, juvenile rheumatoid arthritis; JIA, juvenile idiopathic arthritis; ERA, enthesitis related arthritis; PSA, psoriatic arthritis; UA, undifferentiated arthritis; ESSG, European Spondyloarthropathy Study Group; mNY, modified New York criteria for ankylosing spondylitis; ILAR, International League against Rheumatism; ERA, enthesitis related arthritis; PsA, psoriatic arthritis; UA, undifferentiated arthritis; ASAS, Assessment of Spondyloarthritis International Society. Follow up years refers to mean or median, depending upon the study. Cohort specific details are in footnotes. TNFi: TNF inhibitor usage by end of study.

a $54 \%$ in active disease after $4 y .43 \%$ in remission on meds and $23 \%$ in remission off meds at $4 y$ or within past 6 months.

${ }^{b}$ Status of active or inactive disease during months 9-12. In ERA, 55\% eventually attained disease remission, but at a mean of $\sim 16$ months. 
inactive disease (27). In the Berntson cohort, any signs of sacroiliitis (OR 4.1), enthesitis (OR 2.4) or hip arthritis (OR 2.1) increased the risk for persistent disease. For sacroiliitis alone, $84 \%$ exhibited active disease (21). Herregods et al. noted the association between enthesitis and sacroiliitis in an imaging study, where sacroiliitis was present in $74 \%$ of children with pelvic enthesitis (74). In an Italian MRI study in ERA, early predictors of sacroiliac disease were numbers of active joints and active entheses at onset (24). Earlier studies had also reported an association between high joint count and ultimate development of sacroiliitis; in a study comparing initial patterns of arthritis (pauci vs. poly) between children with JoAS and those with SEA who did not develop axial disease, polyarticular disease at 1 year was highly associated with the development of radiographic sacroiliitis/AS (75). In another study examining joint accumulation over time in a group of children ultimately diagnosed with JoAS, at 6 months after disease onset, only $28.6 \%$ of patients had polyarticular disease, but by 1 year, that number increased to $80 \%(39)$. In a Norwegian ERA cohort, high active joint count at 6 months predicted physical limitation at 23 years (2). Besides high joint count and enthesitis, other risk factors for the development of sacroiliitis include family history of SpA, persistently high ESR and hip arthritis $(2,16,21,24,76)$.

Several studies have examined the influence of HLA-B27 positivity, sex, and their interaction on the presence of sacroiliitis and more directly on prognosis. In a study from Berntson et al. focusing on HLA-B27 across JIA categories in a Nordic cohort, HLA-B27 positivity associated with clinical signs of sacroiliitis (including inflammatory back pain, sacroiliac and buttock pain), enthesitis, and tenosynovitis in boys, but not girls (21). In the whole JIA cohort, boys were more often HLA-B27+ (26\%) vs. $18 \%$ of girls, and boys with ERA had a trend toward clinical signs of sacroiliitis more often than girls (21). In a Norwegian ERA cohort followed over 15 years, male sex also associated with the development of decreased spinal mobility (abnormal Schober test) in $67 \%$ of 36 boys vs. $37 \%$ of 19 girls) (2). However, in a French JoSpA/ERA cohort followed over 5 years, axial disease and sacroiliitis prevalence was equally distributed between sexes (16). In several studies from Taiwan, Germany and Norway, HLA-B27 positivity associated with failure to attain remission $(17,21,25,27)$. The relative odds ratios were around 2 (1.72.2 ), correlating with persistence of active disease after 8 years of 73.2 vs. $59.4 \%$ in the whole JIA cohort $(21,25)$. Interestingly, in the GESPIC and Norwegain cohorts, female sex carried a worse prognosis $(2,17)$. Thus, there have been some cohort or analysis-specific differences regarding sex.

\section{REMISSION RATES AND BIOLOGIC DMARDS}

One possible reason for the relatively poor outcomes noted in various studies, is that the most prominent aspects of JoSpA/ERA (enthesitis and sacroiliitis) do not respond well to conventional synthetic disease modifying anti-rheumatic drugs (DMARDs) such as methotrexate or sulfasalazine (reviewed in another chapter in this issue) $(77,78)$. The data supporting these contentions, mostly obtained from adult studies, has led to revisions in current ACR treatment guidelines supporting earlier use of biologic DMARDs (e.g., TNF inhibitors) following NSAID failure in children with sacroiliitis or enthesitis (79). The IL-17 inhibiting monoclonal antibodies are too new to assess in children, however TNF inhibitors have become much more widespread in use in the 2000s. Trial data has been promising (reviewed in another chapter), but cohorts indicate "real world" application, and how outcomes may be shifting (or not). For simplicity, we will focus on active disease vs. remission over time (Table 3). Over time, there has been a steady increase in biologic DMARD usage, yet a corresponding increase in remission vs. persistent active disease is not yet clear.

A few studies suggest the outlook for ERA may be improving (Table 3), particularly in the short term. For instance, in an openlabel study of JSpA treated with TNF inhibitors, $81 \%(13 / 16)$ achieved clinical remission within 6 months. However, 6/16 (38\%) subsequently flared a median of 2 years after attaining remission (80). In a French study, 69\% of subjects treated with TNF inhibitors experienced inactive disease at 1y, with boys exhibiting a greater response (OR 6.94) (16). Experience in a Canadian cohort (ReACCh-Out) also suggested good short-term gains in SpA; the probability of attaining inactive disease some time during $5 y$ follow up was extremely high, at $>92 \%$ for all SpA categories. Probability of coming off meds during the $5 y$ was $71 \%$ for ERA, $74 \%$ for PsA and $59 \%$ for undifferentiated arthritis. However, overall remission rates at the end of the study were still $<50 \%$ (69). A subset of this same cohort examined a few years later achieved remissions $>60 \%$ (20-35\% with active disease), marking an improvement in outcome, though this may be specific to the two centers examined (70). In a German etanercept cohort, only $52 \%$ of ERA patients attained inactive disease, with $22 \%$ in remission on medication (81). Comparable outcomes were reported in a 2020 comprehensive study on unmet needs in JIA. Brunner et al. described 2 large cohorts, one from Cincinnati Children's (CHMC) and another from the multi-site Childhood Arthritis and Rheumatology Research Alliance (CARRA) registry, including 279/1351 with ERA/PsA and 50/164 with undifferentiated arthritis (82). In the two cohorts, 79 and $72 \%$ of children with ERA/PsA were treated with biologics. Even among those treated with two biologics, 31\% (CHMC) and 55\% (CARRA) still had active disease. While these outcomes are much better than those reported by Minden et al. in 2000 [17\% remission at 5y (83)], there is still obviously room for improvement.

Children with JoSpA/ERA treated with TNF inhibitors may still experience a worse outcome compared to other types of JIA. In the German ICON cohort, even though 30\% of ERA patients were treated with biologic DMARDs, this group took longer than other categories of JIA to attain a state of inactive disease $(9 \mathrm{~m})$ and spent only $27 \%$ of time in inactive disease within the first year (compared to $40 \%$ in the whole JIA cohort). PsA patients spent $25 \%$ in inactive disease. Only 55\% of ERA patients reached inactive disease at a mean of $15.9 \mathrm{~m}$, leaving $45 \%$ with active disease more than a year from enrollment (71). In a study from Taiwan, only $33 \%$ achieved inactive disease, despite high levels of treatment with TNF inhibitors (78\%), an 
outcome that was still significantly worse than for other JIA groups (27). Even within a JIA cohort started on TNF blockers, patients with ERA were much less likely than those with poly JIA (RF-) to attain inactive disease ever (43 vs. $76 \%$ ) or be in inactive disease at $1 \mathrm{y}$ (24 vs. 57\%) (73). Part of the issue may reflect TNFi refractory disease manifestations typical of JoSpA/ERA. For instance, the aggressive hip arthritis may be resistant to TNFi therapy (80). Similarly, TNFi may have limited capacity to suppress progression of sacroiliitis. In the 2014 open label study of etanercept and infliximab, $42 \%$ of children met modified NY AS criteria prior to treatment, and $92 \%$ fulfilled criteria 7 years later (80).

In summary, children with JoSpA/ERA have significant disease burdens and relatively poor outcomes compared to other types of JIA (1). Although most patients initially present with peripheral arthritis and enthesitis, a very high proportion go on to develop axial disease, within the first 5 years of diagnosis $(11,51)$. An alarming number of these children (one third to over one half!) develop "silent" axial disease and have MRI evidence for both acute disease and chronic destructive changes, even in the absence of reported back pain $(49,52)$. Moving forwards, it will be critical to determine if there are other clinical features that correlate more reliably with axial disease. Another possible solution is to treat children diagnosed

\section{REFERENCES}

1. Weiss PF, Beukelman T, Schanberg LE, Kimura Y, Colbert RA, Investigators CR. Enthesitis-related arthritis is associated with higher pain intensity and poorer health status in comparison with other categories of juvenile idiopathic arthritis: the Childhood Arthritis and Rheumatology Research Alliance Registry. J Rheumatol. (2012) 39:2341-51. doi: 10.3899/jrheum.120642

2. Flato B, Hoffmann-Vold AM, Reiff A, Forre O, Lien G, Vinje O. Long-term outcome and prognostic factors in enthesitis-related arthritis: a case-control study. Arthritis Rheum. (2006) 54:3573-82. doi: 10.1002/art.22181

3. Ozgocmen S, Ardicoglu O, Kamanli A, Kaya A, Durmus B, Yildirim K, et al. Pattern of disease onset, diagnostic delay, and clinical features in juvenile onset and adult onset ankylosing spondylitis. J Rheumatol. (2009) 36:2830-3. doi: 10.3899/jrheum.090435

4. Duarte AP, Marques CD, Bortoluzzo AB, Goncalves CR, da Silva JA, Ximenes $\mathrm{AC}$, et al. [Epidemiologic profile of juvenile-onset compared to adult-onset spondyloarthritis in a large Brazilian cohort]. Rev Bras Reumatol. (2014) 54:424-30. doi: 10.1016/j.rbre.2014.06.001

5. Brewerton DA, Hart FD, Nicholls A, Caffrey M, James DC, Sturrock RD. Ankylosing spondylitis and HL-A 27. Lancet. (1973) 1:904-7. doi: 10.1016/S0140-6736(73)91360-3

6. Schlosstein L, Terasaki PI, Bluestone R, Pearson CM. High association of an HL-A antigen, W27, with ankylosing spondylitis. N Engl J Med. (1973) 288:704-6. doi: 10.1056/NEJM197304052881403

7. van der Linden SM, Valkenburg HA, de Jongh BM, Cats A. The risk of developing ankylosing spondylitis in HLA-B27 positive individuals. A comparison of relatives of spondylitis patients with the general population. Arthritis Rheum. (1984) 27:241-9. doi: 10.1002/art.1780270301

8. Dougados M, Baeten D. Spondyloarthritis. Lancet. (2011) 377:2127-37. doi: 10.1016/S0140-6736(11)60071-8

9. Stoll ML, Weiss PF, Weiss JE, Nigrovic PA, Edelheit BS, Bridges SL, et al. Age and fecal microbial strain-specific differences in patients with spondyloarthritis. Arthritis Res Ther. (2018) 20:14. doi: 10.1186/s13075-018-1510-6

10. Gracey E, Burssens A, Cambre I, Schett G, Lories R, McInnes IB, et al. Tendon and ligament mechanical loading in the pathogenesis with JoSpA more aggressively early on, incorporating TNF inhibition for their peripheral arthritis and enthesitis prior to the development of axial disease. Greater TNF inhibitor use may be improving the outcome in this difficult to treat JIA category, particularly in the short term, though more data would be helpful for supporting this idea. The development of sacroiliitis portends a relatively poor prognosis and increased refractoriness to treatment (27). Limited data also suggests axial disease may progress despite TNF inhibitor treatment (80). Thus, the window of opportunity may be limited. At this time, persistently active disease in 30 to $>50 \%$ of children indicates that there is still much to accomplish toward improving the outlook for JoSpA/ERA.

\section{AUTHOR CONTRIBUTIONS}

JS and RB-V conceived the review. JS wrote the first draft of the manuscript. RB-V contributed to revision of the manuscript prior to submission.

\section{FUNDING}

University of Wisconsin-Madison will provide open access publication fees. of inflammatory arthritis. Nat Rev Rheumatol. (2020) 16:193-207. doi: 10.1038/s41584-019-0364-x

11. Burgos-Vargas R, Naranjo A, Castillo J, Katona G. Ankylosing spondylitis in the Mexican mestizo: patterns of disease according to age at onset. $J$ Rheumatol. (1989) 16:186-91.

12. Baek HJ, Shin KC, Lee YJ, Kang SW, Lee EB, Yoo CD, et al. Juvenile onset ankylosing spondylitis (JAS) has less severe spinal disease course than adult onset ankylosing spondylitis (AAS): clinical comparison between JAS and AAS in Korea. J Rheumatol. (2002) 29:1780-5.

13. Jadon DR, Ramanan AV, Sengupta R. Juvenile versus adult-onset ankylosing spondylitis - clinical, radiographic, and social outcomes. a systematic review. J Rheumatol. (2013) 40:1797-805. doi: 10.3899/jrheum. 130542

14. Weiss PF, Colbert RA. Reply. Arthritis Care Res. (2016) 68:1213-4. doi: 10.1002/acr.22885

15. Burgos-Vargas R. The assessment of the spondyloarthritis international society concept and criteria for the classification of axial spondyloarthritis and peripheral spondyloarthritis: a critical appraisal for the pediatric rheumatologist. Pediatr Rheumatol Online J. (2012) 10:14. doi: 10.1186/1546-0096-10-14

16. Goirand M, Breton S, Chevallier F, Duong NP, Uettwiller F, Melki I, et al. Clinical features of children with enthesitis-related juvenile idiopathic arthritis / juvenile spondyloarthritis followed in a French tertiary care pediatric rheumatology centre. Pediatr Rheumatol Online J. (2018) 16:21. doi: 10.1186/s12969-018-0238-9

17. Weiss A, Minden K, Listing J, Foeldvari I, Sieper J, Rudwaleit M. Course of patients with juvenile spondyloarthritis during 4 years of observation, juvenile part of GESPIC. RMD Open. (2017) 3:e000366. doi: 10.1136/rmdopen-2016-000366

18. Rosenberg AM, Petty RE. A syndrome of seronegative enthesopathy and arthropathy in children. Arthritis Rheum. (1982) 25:1041-7. doi: 10.1002/art.1780250902

19. Petty RE, Southwood TR, Manners P, Baum J, Glass DN, Goldenberg J, et al. International league of associations for rheumatology classification of juvenile idiopathic arthritis: second revision, Edmonton, 2001. J Rheumatol. (2004) 31:390-2. 
20. Nordal E, Zak M, Aalto K, Berntson L, Fasth A, Herlin T, et al. Ongoing disease activity and changing categories in a long-term nordic cohort study of juvenile idiopathic arthritis. Arthritis Rheum. (2011) 63:2809-18. doi: 10.1002/art.30426

21. Berntson L, Nordal E, Aalto K, Peltoniemi S, Herlin T, Zak M, et al. HLAB27 predicts a more chronic disease course in an 8-year followup cohort of patients with juvenile idiopathic arthritis. J Rheumatol. (2013) 40:725-31. doi: 10.3899/jrheum.121257

22. Packham JC, Hall MA. Long-term follow-up of 246 adults with juvenile idiopathic arthritis: functional outcome. Rheumatology. (2002) 41:1428-35. doi: 10.1093/rheumatology/41.12.1428

23. Kunjir V, Venugopalan A, Chopra A. Profile of Indian patients with juvenile onset chronic inflammatory joint disease using the ILAR classification criteria for JIA: a community-based cohort study. J Rheumatol. (2010) 37:1756-62. doi: 10.3899/jrheum.090937

24. Pagnini I, Savelli S, Matucci-Cerinic M, Fonda C, Cimaz R, Simonini G. Early predictors of juvenile sacroiliitis in enthesitis-related arthritis. J Rheumatol. (2010) 37:2395-401. doi: 10.3899/jrheum.100090

25. Shen CC, Yeh KW, Ou LS, Yao TC, Chen LC, Huang JL. Clinical features of children with juvenile idiopathic arthritis using the ILAR classification criteria: a community-based cohort study in Taiwan. J Microbiol Immunol Infect. (2013) 46:288-94. doi: 10.1016/j.jmii.2012.03.006

26. Gmuca S, Xiao R, Brandon TG, Pagnini I, Wright TB, Beukelman T, et al. Multicenter inception cohort of enthesitis-related arthritis: variation in disease characteristics and treatment approaches. Arthritis Res Ther. (2017) 19:84. doi: 10.1186/s13075-017-1297-x

27. Shih YJ, Yang YH, Lin CY, Chang CL, Chiang BL. Enthesitis-related arthritis is the most common category of juvenile idiopathic arthritis in Taiwan and presents persistent active disease. Pediatr Rheumatol Online J. (2019) 17:58. doi: 10.1186/s12969-019-0363-0

28. van der Linden S, Valkenburg HA, Cats A. Evaluation of diagnostic criteria for ankylosing spondylitis: a proposal for modification of the New York criteria. Arthritis Rheum. (1984) 27:361-8. doi: 10.1002/art.1780270401

29. Cabral DA, Oen KG, Petty RE. SEA syndrome revisited: a longterm followup of children with a syndrome of seronegative enthesopathy and arthropathy. $J$ Rheumatol. (1992) 19:1282-5.

30. Hall MA, Burgos Vargos R, Ansell BM. Sacroiliitis in juvenile chronic arthritis: a 10-year follow-up. Clin Exp Rheumatol. (1987) 5(Suppl 1):S65-7.

31. Reveille JD. An update on the contribution of the MHC to as susceptibility. Clin Rheumatol. (2014) 33:749-57. doi: 10.1007/s10067-014-2662-7

32. Reveille JD. The genetic basis of spondyloarthritis. Curr Rheumatol Rep. (2004) 6:117-25. doi: 10.1007/s11926-004-0056-6

33. Tikly M, Njobvu P, McGill P. Spondyloarthritis in sub-Saharan Africa. Curr Rheumatol Rep. (2014) 16:421. doi: 10.1007/s11926-014-0421-z

34. Reveille JD. The genetic basis of spondyloarthritis. Ann Rheum Dis. (2011) 70(Suppl 1):i44-50. doi: 10.1136/ard.2010.140574

35. Bowness P. Hla-B27. Annual Rev Immunol. (2015) 33:29-48. doi: 10.1146/annurev-immunol-032414-112110

36. Lopez-Larrea C, Gonzalez-Roces S, Pena M, Dominguez O, Coto E, Alvarez V, et al. Characterization of B27 haplotypes by oligotyping and genomic sequencing in the Mexican Mestizo population with ankylosing spondylitis: juvenile and adult onset. Human Immunol. (1995) 43:174-80. doi: 10.1016/0198-8859(94)00156-K

37. Silva-Ramirez B, Vargas-Alarcon G, Granados J, Burgos-Vargas R. HLA antigens and juvenile onset spondyloarthritides: negative association with non-B27 alleles. Clin Exp Rheumatol. (2005) 23:721-3.

38. O'Shea F, Salonen D, Inman R. The challenge of early diagnosis in ankylosing spondylitis. J Rheumatol. (2007) 34:5-7.

39. Burgos-Vargas R, Vazquez-Mellado J. The early clinical recognition of juvenile-onset ankylosing spondylitis and its differentiation from juvenile rheumatoid arthritis. Arthritis Rheum. (1995) 38:835-44. doi: 10.1002/art.1780380618

40. Phatak S, Mohindra N, Zanwar A, Aggarwal A. Prominent midfoot involvement in children with enthesitis-related arthritis category of juvenile idiopathic arthritis. Clin Rheumatol. (2017) 36:1737-45. doi: 10.1007/s10067-017-3733-3

41. Weiss PF, Chauvin NA, Klink AJ, Localio R, Feudtner C, Jaramillo D, et al. Detection of enthesitis in children with enthesitis-related arthritis: dolorimetry compared to ultrasonography. Arthritis Rheumatol. (2014) 66:218-27. doi: 10.1002/art.38197

42. Mathew AJ, Ostergaard M. Magnetic resonance imaging of enthesitis in spondyloarthritis, including psoriatic arthritis-status and recent advances. Front Med. (2020) 7:296. doi: 10.3389/fmed.2020.00296

43. Rumsey DG, Guzman J, Rosenberg AM, Huber AM, Scuccimarri R, Shiff NJ, et al. Characteristics and course of enthesitis in a juvenile idiopathic arthritis inception cohort. Arthritis Care Res. (2018) 70:303-8. doi: 10.1002/acr.23256

44. Jacobs JC, Berdon WE, Johnston AD. HLA-B27-associated spondyloarthritis and enthesopathy in childhood: clinical, pathologic, and radiographic observations in 58 patients. J Pediatr. (1982) 100:521-8. doi: 10.1016/S0022-3476(82)80746-4

45. Gensler L, Davis JC Jr. Recognition and treatment of juvenileonset spondyloarthritis. Curr Opin Rheumatol. (2006) 18:507-11. doi: 10.1097/01.bor.0000240363.09218.61

46. Calin A, Elswood J. The natural history of juvenile-onset ankylosing spondylitis: a 24-year retrospective case-control study. Br J Rheumatol. (1988) 27:91-3. doi: 10.1093/rheumatology/27.2.91

47. Alvarez-Madrid C, Merino R, De Inocencio J, Garcia-Consuegra J. Tarsitis as an initial manifestation of juvenile spondyloarthropathy. Clin Exp Rheumatol. (2009) 27:691-4. doi: 10.1016/B978-0-444-63596-9.00002-5

48. Burgos-Vargas R, Castelazo-Duarte G, Orozco JA, Garduno-Espinosa J, Clark P, Sanabria L. Chest expansion in healthy adolescents and patients with the seronegative enthesopathy and arthropathy syndrome or juvenile ankylosing spondylitis. J Rheumatol. (1993) 20:1957-60.

49. Weiss PF, Xiao R, Biko DM, Chauvin NA. Assessment of sacroiliitis at diagnosis of juvenile spondyloarthritis by radiography, magnetic resonance imaging, and clinical examination. Arthritis Care Res. (2016) 68:187-94. doi: 10.1002/acr.22665

50. Schiettecatte E, Jaremko JL, Sudol-Szopinska I, Znajdek M, Mandegaran R, Swami V, et al. Common incidental findings on sacroiliac joint MRI in children clinically suspected of juvenile spondyloarthritis. Eur J Radiol Open. (2020) 7:100225. doi: 10.1016/j.ejro.2020.100225

51. Burgos-Vargas R, Clark P. Axial involvement in the seronegative enthesopathy and arthropathy syndrome and its progression to ankylosing spondylitis. $J$ Rheumatol. (1989) 16:192-7.

52. Stoll ML, Bhore R, Dempsey-Robertson M, Punaro M. Spondyloarthritis in a pediatric population: risk factors for sacroiliitis. J Rheumatol. (2010) 37:2402-8. doi: 10.3899/jrheum.100014

53. Maneiro JR, Souto A, Salgado E, Mera A, Gomez-Reino JJ. Predictors of response to TNF antagonists in patients with ankylosing spondylitis and psoriatic arthritis: systematic review and meta-analysis. RMD Open. (2015) 1:e000017. doi: 10.1136/rmdopen-2014-000017

54. Rudwaleit M, Listing J, Brandt J, Braun J, Sieper J. Prediction of a major clinical response (BASDAI 50) to tumour necrosis factor alpha blockers in ankylosing spondylitis. Ann Rheum Dis. (2004) 63:665-70. doi: 10.1136/ard.2003. 016386

55. Marks SH, Barnett M, Calin A. A case-control study of juvenile- and adultonset ankylosing spondylitis. J Rheumatol. (1982) 9:739-41.

56. Marino A, Weiss PF, Brandon TG, Lerman MA. Juvenile spondyloarthritis: focus on uveitis. Pediatr Rheumatol Online J. (2020) 18:70. doi: 10.1186/s12969-020-00463-4

57. Zisman D, Gladman DD, Stoll ML, Strand V, Lavi I, Hsu JJ, et al. The juvenile psoriatic arthritis cohort in the CARRA registry: clinical characteristics, classification, and outcomes. J Rheumatol. (2017) 44:342-51. doi: 10.3899/jrheum.160717

58. Weiss PF, Colbert RA. Juvenile spondyloarthritis: a distinct form of juvenile arthritis. Pediatr Clin North Am. (2018) 65:675-90. doi: 10.1016/j.pcl.2018.03.006

59. Ravelli A, Consolaro A, Schiappapietra B, Martini A. The conundrum of juvenile psoriatic arthritis. Clin Exp Rheumatol. (2015) 33(5 Suppl 93):S40-3.

60. Fragoulis GE, Liava C, Daoussis D, Akriviadis E, Garyfallos A, Dimitroulas T. Inflammatory bowel diseases and spondyloarthropathies: from pathogenesis to treatment. World J Gastroenterol. (2019) 25:2162-76. doi: 10.3748/wjg.v25.i18.2162

61. De Vos M, Cuvelier C, Mielants H, Veys E, Barbier F, Elewaut A. Ileocolonoscopy in seronegative spondylarthropathy. Gastroenterology. (1989) 96(2 Pt 1):339-44. doi: 10.1016/0016-5085(89)91557-6 
62. Ciccia F, Rizzo A, Triolo G. Subclinical gut inflammation in ankylosing spondylitis. Curr Opin Rheumatol. (2016) 28:89-96. doi: 10.1097/BOR.0000000000000239

63. Gracey E, Vereecke L, McGovern D, Frohling M, Schett G, Danese S, et al. Revisiting the gut-joint axis: links between gut inflammation and spondyloarthritis. Nat Rev Rheumatol. (2020) 16:415-33. doi: 10.1038/s41584-020-0454-9

64. Stoll ML, Punaro M, Patel AS. Fecal calprotectin in children with the enthesitis-related arthritis subtype of juvenile idiopathic arthritis. $J$ Rheumatol. (2011) 38:2274-5. doi: 10.3899/jrheum.110508

65. Stamato T, Laxer RM, de Freitas C, Gow R, Silverman ED, Luy L, et al. Prevalence of cardiac manifestations of juvenile ankylosing spondylitis. Am J Cardiol. (1995) 75:744-6. doi: 10.1016/S0002-9149(99)80672-9

66. Ozkan Y. Cardiac involvement in ankylosing spondylitis. J Clin Med Res. (2016) 8:427-30. doi: 10.14740/jocmr2488w

67. Selvaag AM, Aulie HA, Lilleby V, Flato B. Disease progression into adulthood and predictors of long-term active disease in juvenile idiopathic arthritis. Ann Rheum Dis. (2016) 75:190-5. doi: 10.1136/annrheumdis-2014-206034

68. Fantini F, Gerloni V, Gattinara M, Cimaz R, Arnoldi C, Lupi E. Remission in juvenile chronic arthritis: a cohort study of 683 consecutive cases with a mean 10 year followup. J Rheumatol. (2003) 30:579-84.

69. Guzman J, Oen K, Tucker LB, Huber AM, Shiff N, Boire G, et al. The outcomes of juvenile idiopathic arthritis in children managed with contemporary treatments: results from the ReACCh-Out cohort. Ann Rheum Dis. (2015) 74:1854-60. doi: 10.1136/annrheumdis-2015-eular.2400

70. Chhabra A, Robinson C, Houghton K, Cabral DA, Morishita K, Tucker LB, et al. Long-term outcomes and disease course of children with juvenile idiopathic arthritis in the ReACCh-Out cohort: a two-centre experience. Rheumatology. (2020) 59:3727-30. doi: 10.1093/rheumatology/keaa118

71. Sengler C, Klotsche J, Niewerth M, Liedmann I, Foll D, Heiligenhaus A, et al. The majority of newly diagnosed patients with juvenile idiopathic arthritis reach an inactive disease state within the first year of specialised care: data from a German inception cohort. RMD Open. (2015) 1:e000074. doi: 10.1136/rmdopen-2015-000074

72. Guzman J, Henrey A, Loughin T, Berard RA, Shiff NJ, Jurencak R, et al. Predicting which children with juvenile idiopathic arthritis will not attain early remission with conventional treatment: results from the ReACCh-out cohort. J Rheumatol. (2019) 46:628-35. doi: 10.3899/jrheum.180456

73. Donnithorne KJ, Cron RQ, Beukelman T. Attainment of inactive disease status following initiation of TNF-alpha inhibitor therapy for juvenile idiopathic arthritis: enthesitis-related arthritis predicts persistent active disease. J Rheumatol. (2011) 38:2675-81. doi: 10.3899/jrheum.110427

74. Herregods N, Dehoorne J, Pattyn E, Jaremko JL, Baraliakos X, Elewaut D, et al. Diagnositic value of pelvic enthesitis on MRI of the sacroiliac joints in enthesitis related arthritis. Pediatr Rheumatol Online J. (2015) 13:46. doi: 10.1186/s12969-015-0045-5
75. Burgos-Vargas R, Vazquez-Mellado J, Cassis N, Duarte C, Casarin J, Cifuentes $\mathrm{M}$, et al. Genuine ankylosing spondylitis in children: a case-control study of patients with early definite disease according to adult onset criteria. $J$ Rheumatol. (1996) 23:2140-7.

76. Bollow M, Braun J, Biedermann T, Mutze S, Paris S, Schauer-Petrowskaja C, et al. Use of contrast-enhanced MR imaging to detect sacroiliitis in children. Skeletal Radiol. (1998) 27:606-16. doi: 10.1007/s002560050446

77. Haibel H, Brandt HC, Song IH, Brandt A, Listing J, Rudwaleit M, et al. No efficacy of subcutaneous methotrexate in active ankylosing spondylitis: a 16-week open-label trial. Ann Rheum Dis. (2007) 66:419-21. doi: 10.1136/ard.2006.054098

78. Burgos-Vargas R, Vazquez-Mellado J, Pacheco-Tena C, HernandezGarduno A, Goycochea-Robles MV. A 26 week randomised, double blind, placebo controlled exploratory study of sulfasalazine in juvenile onset spondyloarthropathies. Ann Rheum Dis. (2002) 61:941-2. doi: 10.1136/ard.61.10.941

79. Ringold S, Angeles-Han ST, Beukelman T, Lovell D, Cuello CA, Becker ML, et al. 2019 American College of Rheumatology/Arthritis foundation guideline for the treatment of juvenile idiopathic arthritis: therapeutic approaches for non-systemic polyarthritis, sacroiliitis, and enthesitis. Arthritis Rheumatol. (2019) 71:846-63. doi: 10.1002/art.40884

80. Hugle B, Burgos-Vargas R, Inman RD, O'Shea F, Laxer RM, Stimec J, et al. Long-term outcome of anti-tumor necrosis factor alpha blockade in the treatment of juvenile spondyloarthritis. Clin Exp Rheumatol. (2014) 32:42431.

81. Papsdorf V, Horneff G. Complete control of disease activity and remission induced by treatment with etanercept in juvenile idiopathic arthritis. Rheumatology. (2011) 50:214-21. doi: 10.1093/rheumatology/keq292

82. Brunner HI, Schanberg LE, Kimura Y, Dennos A, Co DO, Colbert RA, et al. New medications are needed for children with juvenile idiopathic arthritis. Arthritis Rheumatol. (2020) 72:1945-51. doi: 10.1002/art.41390

83. Minden K, Kiessling U, Listing J, Niewerth M, Doring E, Meincke J, et al. Prognosis of patients with juvenile chronic arthritis and juvenile spondyloarthropathy. J Rheumatol. (2000) 27:2256-63.

Conflict of Interest: The authors declare that the research was conducted in the absence of any commercial or financial relationships that could be construed as a potential conflict of interest.

Copyright (C) 2021 Smith and Burgos-Vargas. This is an open-access article distributed under the terms of the Creative Commons Attribution License (CC BY). The use, distribution or reproduction in other forums is permitted, provided the original author(s) and the copyright owner(s) are credited and that the original publication in this journal is cited, in accordance with accepted academic practice. No use, distribution or reproduction is permitted which does not comply with these terms. 